\title{
Cryptic von Hippel-Lindau disease: germline mutations in patients with haemangioblastoma only
}

F J Hes, S McKee, M J B Taphoorn, P Rehal, R B van der Luijt, R McMahon, J J van der Smagt, D Dow, R A Zewald, J Whittaker, C J M Lips, F MacDonald, P L Pearson, E R Maher

Department of

Medical Genetics,

University Medical

Centre, Utrecht, The

Netherlands

F J Hes

$R$ B van der Luijt

R A Zewald

P L Pearson

Department of Internal Medicine,

University Medical

Centre, Utrecht, The

Netherlands

F J Hes

C J M Lips

West Midlands

Regional Genetics

Service, Birmingham

Women's Hospital,

Edgbaston,

Birmingham B15 2TG,

UK

$S$ McKee

P Rehal

F MacDonald

E R Maher

Department of

Neurology, University

Medical Centre,

Utrecht, The

Netherlands

M J B Taphoorn

East Anglian Genetics

Service,

Addenbrooke's

Hospital, Cambridge,

UK

R McMahon

D Dow

J Whittaker

Clinical Genetics

Centre Leiden, PO

Box 9600, 2300 RC

Leiden, The

Netherlands

$\mathrm{J} J$ van der Smagt

Section of Medical and Molecular Genetics,

Department of

Paediatrics and Child

Health, University of

Birmingham,

Birmingham, UK

E R Maher

Correspondence to:

Professor Maher,

E.R.Maher@bham.ac.uk

Revised version received

1 May 2000

Accepted for publication

26 September 2000

\begin{abstract}
Objectives- Central nervous system haemangioblastoma (HAB) is a major feature of von Hippel-Lindau (VHL) disease, and it is estimated that about $30 \%$ of $\mathrm{HAB}$ patients have VHL disease. Consequently, it is widely recommended that sporadic HAB patients are screened for clinical and radiological features of VHL disease because of the risk of multiple tumours. We investigated the frequency of VHL germline mutations in patients with HAB only with no clinical or radiological evidence of VHL disease to define the role of molecular genetic analysis in the management of such patients.

Methods-Eighty four patients with a single HAB (23 Dutch, $61 \mathrm{UK}$ ) and four with multiple HAB (two Dutch, two UK) were studied by direct sequencing of the coding region and quantitative Southern blotting. Results-A VHL germline mutation was found in three of $69(4.3 \%)$ single HAB patients aged 50 years or less (three of 84 $(3.6 \%)$ total single HAB patients). A germline $V H L$ mutation was detected in a 44 year old woman with a solitary cerebellar HAB, as well as in four clinically unaffected close relatives, and in two single HAB cases presenting at the ages of 29 and 36 years. Germline VHL mutations were detected in two of four cases with multiple HAB.
\end{abstract}

Conclusions-Early detection of VHL disease is important to reduce morbidity and mortality and therefore we recommend that, in addition to conventional clinical and radiological investigations, $V H L$ gene mutation analysis should be offered to all HAB patients younger than 50 years. HAB patients aged $>50$ years will have a lower a priori risk of VHL disease and further data are required to evaluate the role of routine molecular genetic investigations in late onset $\mathrm{HAB}$ cases. The failure to detect germline $V H L$ mutations in some patients with multiple $\mathrm{HAB}$ may indicate the presence of somatic mosaicism or additional HAB susceptibility genes. (f Med Genet 2000;37:939-943)

Keywords: haemangioblastoma; von Hippel-Lindau disease; $V H L$; germline mutation
Haemangioblastomas (HAB) are nonmetastasising tumours of the central nervous system and account for about $2 \%$ of all intracranial tumours. ${ }^{1} \mathrm{HAB}$ arise preferentially in the cerebellum $(\sim 75 \%)$, medulla, and spinal cord $(\sim 25 \%)^{2}$; HAB in the cerebrum are rare. ${ }^{3}$ $\mathrm{HAB}$ are regarded as benign on their histopathological characteristics and do not normally invade the surrounding brain. However, complications may arise because of the tendency of HAB to form expanding cysts, leading to raised or even life threatening intracranial pressure. ${ }^{2}$ They are composed predominantly of vascular and stromal cells. ${ }^{24}$ The frequent presence of haemorrhages and cysts means the tumours vary in morphological appearance. ${ }^{2}$ Four types of HAB can be recognised macroscopically: $5 \%$ are cysts, $60 \%$ predominantly cystic, $26 \%$ predominantly solid, and $9 \%$ solid. ${ }^{5}$

The standard treatment is complete microsurgical removal, ${ }^{5-7}$ aided if necessary by preoperative embolisation to reduce the tumour's vascularity. ${ }^{8}$ Stereotactic radiosurgery shrinks or stops the growth of small or medium sized HAB. ${ }^{7910}$ Adjoining cysts, however, do not respond to radiosurgery and require later and sometimes repeated evacuation.

HAB may occur in sporadic form or as a manifestation of von Hippel-Lindau (VHL) disease. ${ }^{11}$ VHL disease is an autosomal dominant tumour syndrome with an estimated birth incidence of approximately $1 / 36000 .^{12}$ The disease is characterised by a predisposition to bilateral and multifocal tumours. The most common tumours in VHL disease are HAB in the central nervous system and retina, clear cell carcinoma in the kidney, phaeochromocytoma in the adrenal gland, endolymphatic sac tumours in the inner ear, as well as cysts in the kidney, pancreas, and epididymis. In the presence of a positive family history, a diagnosis of VHL disease can be made by the identification of a single retinal or cerebellar HAB, renal cell carcinoma, phaeochromocytoma, or multiple pancreatic cysts in an at risk subject. ${ }^{13}{ }^{14}$ In isolated cases of VHL disease, two or more HABs, or a single HAB in association with a visceral manifestation are required. ${ }^{14}$

The basis of familial inheritance of VHL disease is a germline mutation in the VHL tumour suppressor gene, first identified in 1993 and located in chromosome region $3 \mathrm{p} 25 .{ }^{15}$ In both VHL disease and sporadic HAB, allelic losses and mutations of the VHL tumour suppressor gene affecting stromal cells have been found, 
suggesting that stromal cells represent the neoplastic component of a HAB. ${ }^{416}$ In addition, it was shown that vascular endothelial growth factor (VEGF) is upregulated in stromal cells as a consequence of mutations in the $V H L$ gene. ${ }^{17}$

VHL disease shows variable expression, age dependent penetrance, and a low but consistent new mutation rate. ${ }^{12} 18$ The diagnosis of VHL disease should be considered in all patients with a $\mathrm{HAB}$, as early recognition of a predisposition to develop further $\mathrm{HAB}$ and other tumours (for example, renal cell carcinoma) may reduce morbidity and mortality. The diagnosis of "new mutation" VHL cases is frequently delayed because at least two typical manifestations are required, whereas molecular genetic diagnosis of VHL disease offers the potential to detect subclinical cases of VHL disease in sporadic patients with a single HAB. VHL disease shows complex genotypephenotype correlations. Most VHL gene mutations predispose to $\mathrm{HAB}$, but specific missense mutations may cause high or low risks for renal cell carcinoma or phaeochromocytoma. ${ }^{19-23}$ In addition, rare missense mutations may produce a phaeochromocytoma only phenotype. ${ }^{24-26}$ This suggests that specific VHL gene mutations might cause a HAB only phenotype.

To investigate the genetic epidemiology of HAB in the central nervous system, we performed an international multicentre study of patients with single $\mathrm{HAB}$ and multiple $\mathrm{HAB}$ without evidence of VHL disease (that is, HAB only). As the mean age of VHL patients with $\mathrm{HAB}$ is significantly younger than that for sporadic cases, $29 v 48$ years $^{27}$ (or $33.5 v 43.6$ years in Richard et $a l^{28}$ ), we directed our study towards younger patients with single $\mathrm{HAB}$ as these present the most difficult diagnostic problems in clinical practice.

\section{Patients and methods}

PATIENTS

We investigated two groups of patients with HAB only in the central nervous system. Group 1 consisted of $61 \mathrm{UK}$ and 23 Dutch $\mathrm{HAB}$ patients with a single HAB. These cases were ascertained with the help of neurosurgeons, neurologists, internists, and clinical geneticists. In addition to DNA analysis, all patients underwent clinical examinations for detection of VHL associated tumours (ophthalmological examination and abdominal sonography or MRI) with negative findings. Group 2 consisted of four patients with multiple HABs, but no other evidence of VHL disease (that is, absence of further VHL related tumours) on clinical screening and radiological screening. All patients had histopathologically confirmed HAB at operation.

\section{AGE AT DIAGNOSIS}

Between 1973 and 1996 a total of 182 HAB patients were reported to the National Dutch Pathological Archive (Palga). Fig 1 shows the age at diagnosis of Palga patients as well as patients studied. Details of age distribution of a previous population based cohort of UK HAB patients have been reported previously. ${ }^{27}$

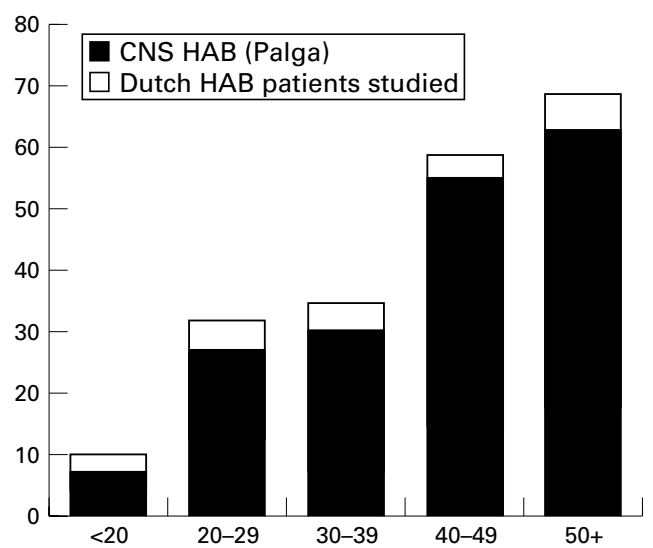

Figure 1 Number of patients and age at diagnosis for 182 patients with haemangioblastoma (HAB) in the central nervous system (CNS) reported in the National Dutch Pathological Archive (Palga) between 1973 and 1996 and 26 Dutch patients in this study with a single $H A B$ between 1996 and 1999.

In 1996, guidelines were distributed via the Dutch newsletter for neurologists on screening all patients with a HAB for a VHL germline mutation. The Dutch patients in the present study were referred for DNA diagnosis from 1996 to 1999 , and the mean age at diagnosis was 37.5 years (range 14-71 years). Compared to unselected cases, the age distribution in the UK as well as in the Dutch cases in this study was biased towards an earlier age at onset.

DNA ANALYSIS

High molecular weight DNA of the probands was isolated from peripheral blood according to established procedures. Exons 1, 2, and 3 of the VHL gene and their immediately flanking sequences were amplified using the polymerase chain reaction. ${ }^{29}$ The flanking sequences included 90 nucleotides upstream of the start codon (the first nucleotide of the coding region is 214) and 45 nucleotides downstream of the stop codon. The nucleotides are numbered according to Latif et $a l^{15}$ (Genbank accession number L15409). PCR products were purified and subjected to sequence analysis using either an $\mathrm{ABI}$ automated sequencer or the dideoxy chain termination reaction with a pUC sequencing kit (Boehringer Mannheim, Mannheim, Germany), using $\gamma-{ }^{35} \mathrm{~S}$ dATP (600 $\mathrm{Ci} / \mathrm{mmol})$. The amplification primers were used as primers in the sequencing reactions. In the UK cases, intragenic mutations were also sought by single strand conformation polymorphism (SSCP).

Screening for genetic rearrangements and deletions was performed by Southern blot analysis, or a novel PCR based deletion assay (Dow et al, in preparation). In Southern blot analysis, DNA was digested with EcoRI alone or with $E c o$ RI and AseI double digest. After gel electrophoresis and transfer to Hybond-N filters, the genomic DNA was hybridised with the VHL g7-cDNA probe, ${ }^{15}$ according to the manufacturer's instruction. Quantitative Southern blotting was performed by hybridising genomic DNA with the VHL g7-cDNA probe and with a beta globin probe, to detect deletions encompassing the entire VHL gene. ${ }^{30}$ 


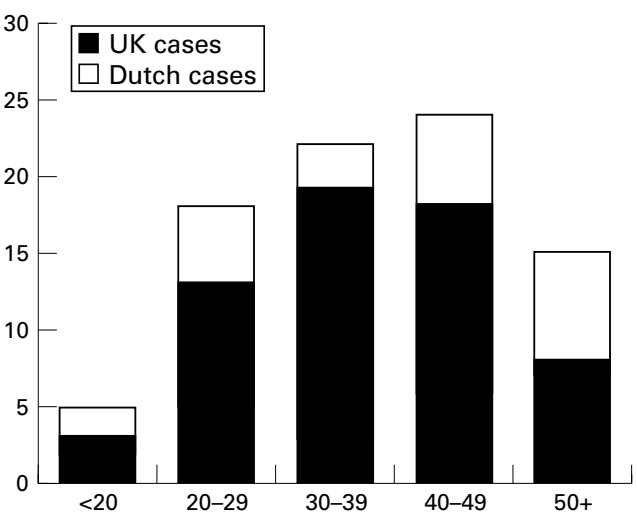

Figure 2 Distribution of single HAB patients (dark = UK, light $=$ Dutch) by age at diagnosis.

\section{Results}

SINGLE HAB

Eighty four cases with single $\mathrm{HAB}$ in the central nervous system (23 Dutch, 61 UK) were investigated. The age distribution of these cases is shown in fig 2. VHL germline mutations were identified in three cases (table 1). The incidence of a $V H L$ germline mutation in single $\mathrm{HAB}$ cases younger than 30 years was $4.3 \%(1 / 23), 30-39$ years was $4.5 \%(1 / 22)$, $40-49$ years was $4.2 \%(1 / 24)$, and 50 years or older was $0 \%(0 / 15)$.

Details of the three germline mutations identified were as follows. (1) A C to T transition at nucleotide 454 was detected in a 44 year old woman (D24) with a single cerebellar HAB (fig 3). This missense mutation leads to a change of proline to serine at codon 81 (P81S) in the VHL protein. DNA analysis of other close relatives showed that four clinically unaffected first and second degree relatives (aged 17-77 years) were also carriers of a P81S germline mutation. (2) A $7 \mathrm{bp}$ frameshift mutation (del 582 GACACAC) was detected in a 29 year old patient (B1) with a single cerebellar HAB with no family history and no evidence of VHL disease on clinical and radiological screening. However, she subsequently developed pancreatic cysts at 34 years of age. (3) A large germline deletion was identified by Southern blot analysis in a 36 year old woman (B2) with a single cerebellar HAB but no other features of VHL disease.

Two patients with a single $\mathrm{HAB}$ developed some additional features of VHL disease during the study: one patient (B1) with a VHL gene mutation (del 582 GACACAC) developed pancreatic cysts (see above) and one patient (B3) developed renal cell carcinoma
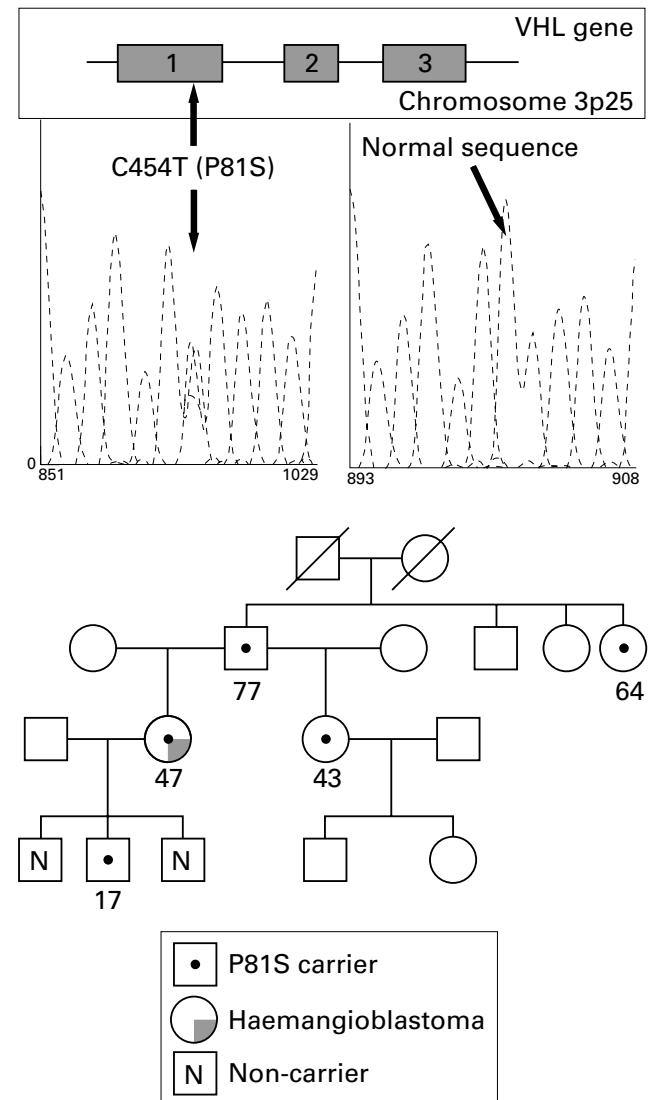

Figure 3 Pedigree of patient D24, showing four clinically unaffected relatives and their ages with the VHL germline mutation P81S.

aged 44 years following a cerebellar $\mathrm{HAB}$ at the age of 40 years, but no VHL mutation was identified.

MULTIPLE HABS

Four patients with multiple HABs (two Dutch and two UK) and without additional VHL related tumours were analysed for VHL germline mutations. Deletions were detected in two patients, (1) a male (B5) with one cerebellar and one medullary $\mathrm{HAB}$ at the age of 40 years, and (2) a male (B6) with multiple spinal HABs at the age of 44 years. Germline mutations were not identified in the two Dutch patients (D13 and D32) with both cerebellar and spinal HABs (aged 44 and 66 years).

\section{Discussion}

We found that the overall risk for finding a VHL germline mutation in a population of 84 patients with a single HAB in the central nerv-

Table 1 Summary of results

\begin{tabular}{|c|c|c|c|c|c|c|}
\hline \multirow[b]{2}{*}{ Patient } & \multirow[b]{2}{*}{ Age } & \multicolumn{2}{|l|}{ Clinical features } & \multirow{2}{*}{$\begin{array}{l}\text { Family } \\
\text { history }\end{array}$} & \multirow[b]{2}{*}{ Mutation } & \multirow{2}{*}{$\begin{array}{l}\text { Previously } \\
\text { reported }\end{array}$} \\
\hline & & $H A B$ & Other & & & \\
\hline D24 & 44 & Solitary cerebellar & - & - & P81S & $21,30,35$ \\
\hline B1 & 29 & Solitary cerebellar & Subsequent pancreatic cysts & - & del 582 GACACAC & No \\
\hline B2 & 36 & Solitary cerebellar & - & - & Deletion & NA \\
\hline B5 & 40 & Cerebellar \& medullary & - & - & Deletion & NA \\
\hline B6 & 44 & Multiple spinal & - & - & Deletion & NA \\
\hline
\end{tabular}

Patient: patient's ID; Age: age at diagnosis, in years; HAB: type and origin of haemangioblastoma; Other: further VHL associated manifestations after clinical screening; Family history: further VHL associated manifestations in family members of proband; Mutation: VHL germline mutation; Previously reported: whether the mutation has been published (references); NA: not applicable. 
ous system and no further features of VHL disease at the time of diagnosis was approximately $4 \%$. In clinical studies of sporadic patients with a HAB it was suggested that a substantial proportion of HAB could be associated with VHL disease upon more detailed examination, that is, $23 \%$ to $34.3 \%$ were found to be affected with VHL disease. ${ }^{6}{ }^{28}$ Molecular genetic analysis of the VHL gene had indicated that sporadic patients with a HAB may have a risk of a VHL gene germline mutation of approximately $10 \%{ }^{31}{ }^{32}$ In our larger study, we found a lower detection rate despite using more sensitive methods of VHL gene analysis, but this is presumably related to the very careful clinical and radiological screening performed before entry into our study. The identification of a VHL germline mutation has important implications for the risk of further tumours and for the risk of VHL disease in relatives, so the identification of a VHL mutation in a significant proportion of single HAB patients despite conventional clinical and radiological investigation is important.

Statistical analysis of the age at onset of HAB in VHL disease and non-VHL cases (based on clinical criteria) is consistent with a one and two hit tumourigenesis model as predicted by the Knudson hypothesis. ${ }^{27}$ Mean age at diagnosis of cerebellar HAB in VHL disease is younger than in sporadic cases (29 years versus 48 years, respectively) so we anticipated a higher incidence of unsuspected VHL gene mutations in early onset cases. In addition, older patients with VHL gene mutations would be more likely to manifest other evidence of VHL disease and so be excluded from our study. Thus, although our results were broadly compatible with this hypothesis, the identification of germline VHL gene mutations in two of a group of 46 patients aged 30 to 49 years with a single $\mathrm{HAB}$ and no clinical or radiological features of VHL disease suggests that molecular genetic analysis should be used in all single HAB patients younger than 50 years. For older onset patients, the frequency of germline mutations is likely to be less (see above) and larger research based studies are required to define whether molecular genetic analysis should be performed when clinical and radiological screening has shown no evidence of VHL disease.

A major strength of the present study was the use of recently developed techniques to detect large germline deletions. Before the introduction of these techniques, there was a VHL germline mutation detection rate (with Southern blotting and sequencing of the coding region) of approximately $80 \%$ in known VHL families. ${ }^{22}$ However, methods to detect large deletions (for example, quantitative Southern blotting) have significantly increased the detection rate, reaching $100 \%$ in proven familial VHL disease. ${ }^{30}$ Therefore a conservative estimate of the mutation detection sensitivity of the strategy used in this study would be in the order of $95 \%$. Although other studies of sporadic patients with a $\mathrm{HAB}$ have used less sensitive techniques, ${ }^{31-33}$ it is of interest that Oberstrass et $a l^{\beta 1}$ detected a germline mutation in two of 20 patients (aged 18 and 40 years) with HAB of the central nervous system (although no data were available about a possible family history of VHL disease). Decker et $a l^{33}$ reported a 29 year old patient with recurrent spinal $\mathrm{HAB}$, a negative family history of VHL disease, and a de novo frameshift VHL gene exon 2 mutation. However, this case was not comparable to those in our study because a renal mass and pancreatic and renal cysts were detected on clinical screening. In a series of 18 sporadic patients with a $\mathrm{HAB}$, Olschwang et a ${ }^{32}$ found a missense mutation in two patients (42 and 56 years of age) without clinical investigations showing any evidence of VHL disease. The latter case would only have been detected by also screening single $\mathrm{HAB}$ patients aged over 50 years for a VHL gene mutation.

Although specific missense VHL mutations may cause a phaeochromocytoma only phenotype, ${ }^{24-26}$ we did not find unequivocal evidence for $V H L$ gene mutations that would predispose to a HAB only phenotype. However, the VHL germline mutation (P81S) that was found in a 44 year old woman with a solitary $\mathrm{HAB}$ and in four clinically unaffected family members was associated with an unusually low penetrance within this family. To reduce the possibility of a genetic polymorphism, 50 non-VHL patients were sequenced. Sequence analysis of exon 1 showed that all persons were homozygous for nucleotide 545C (data not shown). Phenotypic expression in VHL disease is influenced by allelic heterogeneity, stochastic events, and genetic modifiers. ${ }^{34}$ The P81S mutation has been reported four times previously: (1) in an isolated German patient with a full blown VHL tumour spectrum (cerebellar and spinal HAB, renal cell carcinoma, and renal, pancreatic, and epididymal cysts); (2) in a 34 year old American patient with HAB only; (3) in a 35 year old American patient with retinal haemangioblastoma and islet cell tumour of the pancreas (the father is the only other relative with a VHL related tumour and had a phaeochromocytoma); and (4) in an isolated Japanese patient with multiple HABs and a renal cell carcinoma. ${ }^{213035}$ These findings suggest that P81S mutation carriers in the family are also at risk of renal cell carcinoma. Moreover, only one of the P81S carriers had affected family members, which may imply that this missense mutation has a low penetrance.

Interestingly, we did not find VHL germline mutations in two of the four patients with multiple HABs. As the presence of two or more retinal or cerebellar $\mathrm{HAB}$ satisfies the strict diagnostic criteria for VHL disease, ${ }^{12}{ }^{14}$ this was an unexpected finding in the light of the high sensitivity of the mutation detection methods used, and could perhaps indicate additional HAB susceptibility gene(s). Alternative explanations would include a mutation in part of the VHL gene not analysed (for example, regulatory domain) or somatic mosaicism. In this context it is interesting that the two multiple $\mathrm{HAB}$ patients with germline mutations had the earliest age at onset and the patients with later onset may be mosaic and so have a milder phe- 
notype or represent phenocopies (independent mutation events giving rise to various $\mathrm{HAB}$ could also be expected by chance). Although mosaicism has so far been described infrequently in VHL disease, ${ }^{36}$ it seems likely that it will be relatively common, as in neurofibromatosis type $2 .^{37}$

We have shown that VHL gene mutation analysis facilitates the management of sporadic patients with $\mathrm{HAB}$ and recommend that it should be performed in all patients younger than 50 years with a single $\mathrm{HAB}$ even if there is no other clinical or radiological evidence of VHL disease. Although the detection rate in older patients should be lower, we suggest that such patients need to be studied on a research basis, using the latest mutation detection strategies to define cost-benefit consequences for molecular genetic analysis of this group of patients.

F J Hes received grants from Zorg Onderzoek Nederland and the Janivo Foundation. The VHL g7-cDNA probe was kindly provided by I Kuzmin, Frederick, MD, USA. The beta globin probe was kindly provided by C Stolle, Philadelphia, PA, USA We thank Dr H P H Neumann, Freiburg, Germany, Dr C Stolle, Philadelphia, PA, USA, Dr G Glenn, Rockville, MD, USA, and Philadelphia, PA, USA, Dr G Glenn, Rockville, MD, USA, and
Dr Masahiro Yao, Yokohama, Japan for clinical data on P81S carriers.

1 Ellison D, Love S, Chimelli L, Harding B, Lowe J, Roberts GW, Vinters HV. Miscellaneous neoplasms: hemangioblastoma. In Hodgson S, ed. Neuropathology, a reference text of toma. In Hodgson S, ed. Neuropathology, a reference

2 Wizigmann Voos S, Plate KH. Pathology, genetics and cell biology of hemangioblastomas. Histol Histopathol 1996;11: biology of

3 Russell D, Rubenstein LJ. Pathology of tumours of the central nervous system. Vol 5. London: Edward Arnold, 1989:63957.

4 Vortmeyer AO, Gnarra JR, Emmert-Buck MR, Katz D, Linehan WM, Oldfield EH, Zhuang Z. von Hippel-Linda gene deletion detected in the stromal cell component of a cerebellar hemangioblastoma associated with von HippelLindau disease. Hum Pathol 1997;28:540-3.

5 Richard S, Campello C, Taillandier L, Parker F, Resche F. Haemangioblastoma of the central nervous system in von Hippel-Lindau disease. French VHL Study Group. F Intern Med 1998;243:547-53.

6 Neumann HP, Eggert HR, Weigel K, Friedburg H, Wiestler OD, Schollmeyer, P. Hemangioblastomas of the central nervous system. A 10 -year study with special reference to nervous system. A 10-year study with special reference to

7 von Hippel-Lindau syndrome. F Neurosurg 1989;70:24-30. C. Gamma knife radiosurgery in 11 hemangioblastomas. $\mathcal{F}$ C. Gamma knife radiosurger

8 Tampieri D, Leblanc R, TerBrugge K. Preoperative embolization of brain and spinal hemangioblastomas. Neurosurgery 1993;33:502-5.

9 Chang SD, Meisel JA, Hancock SL, Martin DP, McManus M, Adler JR Jr. Treatment of hemangioblastomas in von Hippel-Lindau disease with linear accelerator-based radiosurgery. Neurosurgery 1998;43:28-34.

10 Patrice SJ, Sneed PK, Flickinger JC, Shrieve DC, Pollock BE, Alexander E, Larson DA, Kondziolka DS, Gutin PH, Wara WM, McDermott MW, Lunsford LD, Loeffler JS Radiosurgery for hemangioblastoma: results of a multiinstitutional experience. Int $f$ Radiat Oncol Biol Phys 1996;35:493-9.

11 Huson SM, Harper PS, Hourihan MD, Cole G, Weeks RD, Compston DA. Cerebellar haemangioblastoma and von Hippel-Lindau disease. Brain 1986;109:1297-310.

12 Maher ER, Iselius L, Yates JR, Littler M, Benjamin C, Harris R, Sampson J, Williams A, Ferguson Smith MA, Morton N. Von Hippel-Lindau disease: a genetic study. $\mathscr{F}$ Med Genet 1991;28:443-7.

13 Melmon KL, Rosen SW. Lindau's disease: review of the literature and study of a large kindred. $A m f \mathrm{Med}$ 1964;36:595-617.

14 Maher ER, Kaelin WG Jr. Von Hippel-Lindau disease. Medicine 1997;76:381-91.

15 Latif F, Tory K, Gnarra J, Yao M, Duh FM, Orcutt ML Stackhouse T, Kuzmin I, Modi W, Geil L, Schmidt L, Zhou $\mathrm{FW}, \mathrm{Li} \mathrm{H}$, Wei MH, Chen F, Glenn GM, Choyke PL, Walther MM, Weng Y, Duan DR, Dean M, Glavac D, Richards FM, Crossey PA, Ferguson Smith MA, Paslier ID, Chumakov I, Cohen D, Chinault AC, Maher ER, Linehan WM, Zbar B, Lerman MI. Identification of the von Hippel-Lindau disease tumor suppressor gene. Science 1993;260:1317-20.

16 Lee JY, Dong SM, Park WS, Yoo NJ, Kim CS, Jang JJ, Chi JG, Zbar B, Lubensky IA, Linehan WM, Vortmeyer AO, Zhuang Z. Loss of heterozygosity and somatic mutations of the VHL tumor suppressor gene in sporadic cerebellar hemangioblastomas. Cancer Res 1998;58:504-8.
17 Stratmann R, Krieg M, Haas R, Plate KH. Putative control of angiogenesis in hemangioblastomas by the von HippelLindau tumor suppressor gene. $\mathcal{F}$ Neuropathol Exp Neurol 1997;56:1242-52.

18 Richards FM, Payne SJ, Zbar B, Affara NA, Ferguson Smith MA, Maher ER. Molecular analysis of de novo germline mutations in the von Hippel-Lindau disease gene. Hum Mol Genet 1995;4:2139-43.

19 Crossey PA, Richards FM, Foster K, Green JS, Prowse A, Latif F, Lerman MI, Zbar B, Affara NA, Ferguson Smith MA, Maher ER. Identification of intragenic mutations in the von Hippel-Lindau disease tumour suppressor gene and correlation with disease phenotype. Hum Mol Genet 1994;3:1303-8.

20 Chen F, Slife L, Kishida T, Mulvihill J, Tisherman SE, Zbar B. Genotype-phenotype correlation in von Hippel-Lindau disease: identification of a mutation associated with VHL type 2A. F Med Genet 1996;33:716-17.

21 Zbar B, Kishida T, Chen F, Schmidt L, Maher ER, Richards FM, Crossey PA, Webster AR, Affara NA, Ferguson Smith MA, Brauch H, Glavac D, Neumann HPH, Tisherman S, Mulvihill JJ, Gross DJ, Shuin T, Whaley J, Seizinger B, Kley N, Olschwang S, Boisson C, Richard S, Lips CJM, Linehan WM, Lerman M. Germline mutations in the von Hippel-Lindau disease (VHL) gene in families from North America, Europe and Japan. Hum Mutat 1996;8:348-57.

22 Maher ER, Webster AR, Richards FM, Green JS, Crossey PA, Payne SJ, Moore AT. Phenotypic expression in von Hippel-Lindau disease: correlations with germline VHL gene mutations. $\mathcal{F}$ Med Genet 1996;33:328-32.

23 Brauch H, Kishida T, Glavac D, Chen F, Pausch F, Hofler $\mathrm{H}$, Latif F, Lerman MI, Zbar B, Neumann HP. Von Hippel-Lindau (VHL) disease with pheochromocytoma in the Black Forest region of Germany: evidence for a founder effect. Hum Genet 1995;95:551-6.

24 Crossey PA, Eng C, Ginalska Malinowska M, Lennard TW, Wheeler DC, Ponder BA, Maher ER. Molecular genetic diagnosis of von Hippel-Lindau disease in familial phaeochromocytoma. $\mathcal{F}$ Med Genet 1995;32:885-6.

25 Neumann HP, Eng C, Mulligan LM, Glavac D, Zauner I, Ponder BA, Crossey PA, Maher ER, Brauch H. Consequences of direct genetic testing for germline mutations in the clinical management of families with multiple endocrine neoplasia, type II. $\mathcal{F} A M A$ 1995;274:1149-51

26 Woodward ER, Eng C, McMahon R, Voutilainen R, Affara NA, Ponder BA, Maher ER. Genetic predisposition to phaeochromocytoma: analysis of candidate genes GDNF, RET and VHL. Hum Mol Genet 1997;6:1051-6.

27 Maher ER, Yates JR, Ferguson Smith MA. Statistical analysis of the two stage mutation model in von Hippel-Lindau disease, and in sporadic cerebellar haemangioblastoma and renal cell carcinoma. $\mathcal{F}$ Med Genet 1990;27:311-14.

28 Richard S, Beigelman C, Gerber S, Van Effenterre R, Gaudric A, Sahel M, Binaghi M, de Kersaint Gilly A, Houtteville JP, Brunon JP, Guerin J, Cornu P, Redondo A, Huth M, JP, Brunon JP, Guerin J, Cornu P, Redondo A, Huth M,
Resche F. [Does hemangioblastoma exist outside von Hippel-Lindau disease?] L'hemangioblastome existe-t-il en dehors de la maladie de von Hippel-Lindau? Neurochirurgie 1994;40:145-54

29 Gnarra JR, Tory K, Weng Y, Schmidt L, Wei MH, Li H, Latif F, Liu S, Chen F, Duh FM, Lubensky I, Duan DR, Florence C, Pozatti R, Walther MM, Bander NH, Grossman HB, Brauch H, Pomer S, Brooks JD, Isaacs WB, Lerman MI, Zbar B, Linehan WM. Mutations of the VHL tumour supp

30 Stolle C, Glenn G, Zbar B, Humphrey JS, Choyke P, Walther M, Pack S, Hurley K, Andrey C, Klausner R, Linehan WM. Improved detection of germline mutations in the von Hippel-Lindau disease tumor suppressor gene. Hum Mutat 1998;12:417-23.

31 Oberstrass J, Reifenberger G, Reifenberger J, Wechsler W, Collins VP. Mutation of the Von Hippel-Lindau tumour suppressor gene in capillary haemangioblastomas of the central nervous system. F Pathol 1996;179:151-6.

32 Olschwang S, Richard S, Boisson C, Giraud S, LaurentPuig P, Resche F, Thomas G. Germline mutation profile of the VHL gene in von Hippel-Lindau disease and in sporadic hemangioblastoma. Hum Mutat 1998;12:424-30.

33 Decker HJ, Neuhaus C, Jauch A, Speicher M, Ried T, Bujard M, Brauch H, Storkel S, Stockle M, Seliger B, Huber C. Detection of a germline mutation and somatic homozygous loss of the von Hippel-Lindau tumorsuppressor gene in a family with a de novo mutation. A suppressor gene in a family with a de novo mutation. A SSCP, FISH, and CGH. Hum Genet 1996;97:770-6.

34 Webster AR, Richards FM, MacRonald FE, Moore AT, Maher ER. An analysis of phenotypic variation in the familial cancer syndrome von Hippel-Lindau disease: evidence for modifier effects. Am F Hum Genet 1998;63: 1025-35.

35 Japan CRGfVi. Germline mutations in the von HippelLindau disease (VHL) gene in Japanese VHL. Hum Mol Genet 1995;4:2233-7.

36 Sgambati MT, Stolle C, Choyke PL, Walther MM, Zbar B, Linehan WM, Glenn GM. Mosaicism in von HippelLindau disease: lessons from kindreds with germline mutations identified in offspring with mosaic parents. Am f Hum Genet 2000;66:84-91.

37 Evans DG, Wallace AJ, Wu CL, Trueman L, Ramsden RT, Strachan T. Somatic mosaicism: a common cause of classic Strachan T. Somatic mosaicism: a common cause of classic
disease in tumor-prone syndromes? Lessons from type 2 neurofibromatosis. Am f Hum Genet 1998;63:727-36. 